\title{
AMBIENTE FÍSICO E SIGNIFICADO AMBIENTAL NO PROCESSO DE RESTAURAÇÃO DO ESTRESSE EM QUARTOS DE INTERNAÇÃO PEDIÁTRICA
}

\author{
ENTORNO FÍSICO Y SIGNIFICADO AMBIENTAL EN EL PROCESO DE RESTAURACIÓN DEL ESTRÉS \\ EN SALAS DE ADMISIÓN PEDIÁTRICA
}

\section{PHYSICAL ENVIRONMENT AND ENVIRONMENTAL MEANING IN THE STRESS RESTORATION PROCESS IN PAEDIATRIC HOSPITAL ROOMS}

\section{FELIPPE, MAÍRA LONGHINOTTI}

Doutora em Tecnologia da Arquitetura, Professora do Departamento de Arquitetura e Urbanismo e do Programa de Pós-Graduação em Arquitetura e Urbanismo, Universidade Federal de Santa Catarina, m.l.felippe@ufsc.br

\section{HODECKER, MAÍSA}

Psicóloga, Mestranda em Psicologia, Universidade Federal de Santa Catarina , maisa_hodecker@hotmail.com

\section{PICHETTI, DANIELLA ZICHTL C. M.}

Graduanda em Psicologia, Universidade Federal de Santa Catarina, danipichetti@gmail.com

\section{KUHNEN, ARIANE}

Doutora em Ciências Humanas, Professora do Programa de Pós-Graduação em Psicologia, Universidade Federal de Santa Catarina, ariane.kuhnen@ufsc.br

\section{RESUMO}

As mensagens comunicadas pelo ambiente físico são consideradas uma fonte de estresse nos hospitais quando não correspondem às expectativas ambientais dos pacientes. No presente estudo, hipotetiza-se que 0 ambiente físico hospitalar consinta a recuperação a partir do estresse, caso suscite cognições e afetos de valência positiva. Desse modo, buscou-se identificar atributos físicos visuais de quartos de internação pediátricos que comunicam aos pacientes mensagens ambientais ligadas ao processo de restauração afetiva do estresse. Participaram da investigação 50 pacientes, com idade superior aos 8 anos. A pesquisa se deu em quartos de um hospital pediátrico da Região Sul do Brasil, por meio de entrevistas semiestruturadas a partir de fotografias. Os resultados indicaram que quartos percebidos pelos pacientes como ambientes restauradores foram vistos caracteristicamente como lugares confortáveis, mas também como ambientes alegres, bonitos, tranquilos e reconfortantes. Ao se estabelecer uma correspondência entre esses significados ambientais e os atributos físicos visuais que os geram, este estudo concluiu que as seguintes características do quarto de internação desempenham um papel na comunicação de mensagens ligadas ao processo restaurador: (a) mobiliário adequado; (b) ambiente colorido; (c) acesso visual ao ambiente exterior; (d) acesso a equipamentos que podem oferecer distração positiva; (e) amplitude; e (f) organização da estrutura hospitalar. $\mathrm{O}$ estudo de ambientes restauradores através da análise do significado ambiental mostrou-se pertinente, lançando luz sobre alguns dos aspectos que podem promover o bem-estar do paciente pediátrico.

PALAVRAS-CHAVE: Psicologia Ambiental; ambientes restauradores; significado ambiental; hospital pediátrico; percepção ambiental.

\section{RESUMEN}

Los mensajes comunicados por el entorno físico se consideran una fuente de estrés en los hospitales cuando no cumplen con las expectativas ambientales de los pacientes. En el presente estudio, se hipotetiza que el entorno físico del hospital permitirá la recuperación del estrés si aumenta las cogniciones y afectos de valencia positiva. Por lo tanto, buscamos identificar los atributos físicos visuales de las salas de hospitalización pediátrica que comunican a los pacientes mensajes ambientales relacionados con el proceso de restauración afectiva del estrés. Cincuenta pacientes mayores de 8 años participaron en la investigación. La investigación tuvo lugar en habitaciones de un hospital pediátrico en el sur de Brasil, a través de entrevistas semiestructuradas basadas en fotografías. Los resultados indicaron que las habitaciones percibidas por los pacientes como ambientes restaurativos se veían característicamente como lugares cómodos, pero también como ambientes alegres, hermosos, pacíficos y reconfortantes. Al establecer una correspondencia entre estos significados ambientales y los atributos físicos visuales que los generan, este estudio concluyó que las siguientes características de la sala de hospitalización desempeñan un papel en la comunicación de los mensajes del proceso restaurativo: (a) mobiliario adecuado; (b) ambiente colorido; (c) acceso visual al entorno exterior; (d) acceso a equipos que pueden ofrecer distracción positiva; (e) amplitud; y (f) organización de la estructura del hospital. El estudio de los entornos restaurativos a través del análisis de lo significado ambiental ha demostrado ser pertinente, arrojando luz sobre algunos de los aspectos que pueden promover el bienestar de los pacientes pediátricos. PALABRAS CLAVES: Psicologia Ambiental; ambientes restaurativos; significado ambiental; hospital pediátrico; percepción ambiental. 


\section{ABSTRACT}

Messages communicated by the physical environment are considered a source of stress in hospitals when they do not meet patients' environmental expectations. In the present study, it is hypothesized that the hospital physical environment will allow stress recovery if it raises positive cognitions and affects. Thus, we sought to identify visual physical attributes of paediatric inpatient rooms that communicate to patients environmental messages linked to stress restoration process. Fifty patients aged over 8 years participated in the investigation. The research took place in inpatient rooms of a paediatric hospital in Southern Brazil, through semistructured interviews based on photographs. The results indicated that rooms perceived by patients as restorative environments were characteristically seen as comfortable places, but also as cheerful, beautiful, peaceful and comforting environments. By establishing a correspondence between these environmental meanings and the visual physical attributes that generate them, this study concluded that the following characteristics of the hospital room play a role in communicating messages linked to the restoration process: (a) adequate furniture; (b) colourful environment; (c) visual access to the outdoor environment; (d) access to equipment that may offer positive distraction; (e) amplitude; and (f) organization of the hospital structure. The study of restorative environments through the analysis of environmental meaning has shown to be pertinent, shedding light on some of the aspects that may promote paediatric patients' well-being.

KEYWORDS: Environmental Psychology; restorative environments; environmental meaning; pediatrics hospital; environmental perception.

\section{INTRODUÇÃO}

Há entendimento de que tanto a hospitalização como o ambiente hospitalar podem constituir-se como estressores para pacientes. Interrupção de hábitos e rotinas, despersonalização, falta de controle, privacidade e conforto, mal-estar físico, são apenas alguns dos aspectos envolvidos na produção de estresse em hospitais (SAID et al., 2005). Crianças são, comumente, ainda mais vulneráveis a esses fatores, percebendo-os como uma ameaça de um modo mais agudo que os adultos (BONNES; FORNARA; BONAIUTO, 2008). As reações fisiológicas e psicológicas de estresse, a sua vez, podem prejudicar o processo de recuperação do paciente, interferindo negativamente na resposta do sistema imunológico e nos resultados de exames médicos (ULRICH, 2001).

Um dos fatores apontados pela literatura como um estressor em hospitais está ligado à atribuição de sentido ao ambiente hospitalar, ou seja, ao chamado 'significado ambiental' (SHUMAKER; REIZENSTEIN, 1982), entendido como o conjunto de acepções utilizadas por uma pessoa para definir e dotar de valor um lugar (RAPOPORT, 1990). O modo como um indivíduo reage ao ambiente é regulado, entre outros, pelos significados ambientais elaborados por esse indivíduo em sua relação com o meio ao longo da vida. Então, a reação emocional a um ambiente se dá, entre outros, em função de seu sentido, historicamente construído pelo observador, assumindo tal significado um papel de mediador entre o meio físico e a resposta afetiva (FELIPPE, 2015).

Se o significado ambiental pode ser um fator de estresse, entende-se também que, na direção contrária, tem potencial para se constituir como elemento não estressor, permitindo respostas psicofisiológicas, como a restauração da saúde e do bem-estar. Restauração é um processo de recuperação de recursos ou habilidades comprometidos (HARTIG, 2011), como os recursos afetivos, cognitivos, comportamentais e fisiológicos mobilizados em razão de algum estressor. Ambientes que suscitam mensagens positivas se configurariam, desse modo, como potenciais ambientes restauradores, isto é, ambientes que, como afirma Hartig (2011), permitem ou até mesmo promovem o processo restaurador.

Essa hipótese foi recentemente testada em um estudo desenvolvido na Itália, com pacientes pediátricos, em quartos de internação hospitalar (FELIPPE, 2015; FELIPPE et al., 2017). Na pesquisa foi possível estabelecer empiricamente uma relação entre significado ambiental e restauração afetiva a partir da condição de estresse. Uma melhor avaliação ambiental foi associada a uma maior restauração. Além disso, a restauração foi também maior quanto mais os pacientes consideravam o quarto de internação reconfortante, ordenado, alegre, relaxante, cômodo, dotado de ar fresco, espaçoso, agradável e vivaz.

Esses achados sugerem que a promoção de relações de bem-estar nos hospitais passa pelo entendimento do modo como as pessoas percebem e dão significado a esses espaços e, fundamentalmente, depende do conhecimento acerca das características físico-ambientais que, para determinado grupo social, desempenham um papel importante na comunicação de certos sentidos e valores. Assim, o objetivo mais amplo do estudo aqui relatado foi identificar os atributos físicos visuais de quartos de internação pediátricos que comunicam aos pacientes mensagens ambientais ligadas ao processo de restauração afetiva do estresse. De modo específico, esta investigação procurou (a) identificar quartos de internação pediátricos percebidos pelos pacientes como ambientes restauradores do estresse afetivo; (b) examinar as mensagens comunicadas por esses ambientes; (c) estabelecer uma correspondência entre as mensagens ambientais suscitadas e os atributos físicos visuais que as geram; (d) comparar os resultados obtidos aos encontrados em estudo anterior similar realizado em um contexto cultural diferente.

O estudo relatado nesse artigo foi executado na Região Sul do Brasil e se inseriu em um projeto de pesquisa sobre atributos físicos e significado ambiental no processo de restauração do estresse em hospitais, desenvolvido em um primeiro momento a partir de dados coletados na Itália (FELIPPE, 2015; 
FELIPPE et al., 2017). Dado que o significado atribuído a um lugar é influenciado, entre outros, pelo ambiente social, físico e cultural, bem como pela trajetória pessoal dos seus usuários, entende-se que as características específicas de contexto e mesmo da amostra podem gerar resultados diversos de um lugar a outro. Por esse motivo, a presente proposta visa obter dados válidos para uma amostra brasileira que também possam ser comparados àqueles obtidos em um contexto cultural diferente.

Como trata-se de pesquisa com seres humanos, o projeto foi submetido ao Comitê de Ética da Universidade Federal de Santa Catarina, e aprovado em 23 de agosto de 2016, pelo parecer n. 1.691.934.

\section{MÉTODO}

O estudo empregou uma estratégia de investigação qualitativo-quantitativa e assumiu um perfil descritivo. Ocorreu em quartos de internação de um hospital infantil público, de alta especialização e relevância nacional, que atende tanto a pacientes da região mais imediata, como provenientes de todo o estado federativo do qual faz parte. A investigação ocorreu em quartos pertencentes a diferentes unidades de internação do hospital, que comportam ambientes com três a seis leitos.

\section{Participantes}

Participaram do estudo pacientes em idade pediátrica em regime de internação hospitalar. Os critérios de inclusão dos participantes na amostra investigada foram: (a) ter idade superior aos 8 anos; (b) ser capaz de tomar parte do estudo por não apresentar quadro clínico coibente, como comprometimento crônico de habilidades cognitivas, dor aguda, estado de sofrimento; (c) não ter sido diagnosticado com patologia transmissível pelo contato, para se evitar a transmissão de patógenos entre pacientes através do material de pesquisa. Os critérios de inclusão foram idênticos aos utilizados em estudo similar desenvolvido na Itália (FELIPPE, 2015), a partir do qual se pretende realizar uma discussão comparativa. No referido estudo, a idade dos participantes foi determinada em função de observações realizadas durante um estudo-piloto, no qual pacientes com idade inferior aos 8 anos não demonstraram habilidades de compreensão e expressão para responder de modo satisfatório ao grupo de instrumentos utilizados.

No presente estudo, para a determinação da quantidade final de participantes foi utilizado o critério da amostragem por saturação (FONTANELLA; RICAS; TURATO, 2008). A partir do $45^{\circ}$ participante, o conteúdo das respostas fornecidas ao instrumento de pesquisa foi codificado. As entrevistas subsequentes puderam ser codificadas nas categorias definidas para as 45 primeiras entrevistas, sem acréscimo de novos elementos temáticos. Após a quinta entrevista em que se percebeu tal repetição de informações, optou-se pelo encerramento da coleta dos dados, sendo obtido um total de 50 entrevistados.

\section{Instrumento}

$O$ instrumento condutor da pesquisa foi uma entrevista individual semiestruturada, realizada a partir de questões abertas elaboradas pelos pesquisadores. A entrevista se desenvolveu a partir de fotografias de quartos de internação, que assumiram a função de modelo (NEIVA-SILVA; KOLLER, 2002): foram estímulos apresentados para que os participantes comunicassem suas percepções acerca das imagens que Ihes eram propostas. Ao todo foram utilizadas12 fotografias na entrevista, apresentadas na Figura 1. São registros fotográficos de quartos do próprio hospital de estudo, adicionados a imagens utilizadas em pesquisa similar comparativa (FELIPPE, 2015). A seleção de imagens se deu a partir de um conjunto mais amplo de fotografias (32 registros), com o auxílio de cinco juízes, estudantes de Psicologia, de modo a se eliminar registros semelhantes entre si.

As imagens utilizadas durante a entrevista foram impressas a cores em papel fotográfico 7 por $10 \mathrm{~cm}$, posteriormente laminadas com adesivo transparente fosco e coladas sobre um suporte rígido imantado nas mesmas dimensões da imagem. Foram dispostas aleatoriamente sobre um quadro metálico preto magnético, de dimensões 54 por $54 \mathrm{~cm}$, e apresentadas ao paciente, que pode arrastá-las livremente sobre a superfície do quadro.

A entrevista iniciou com a apresentação de um cenário hipotético, em que o paciente foi convidado a se imaginar em uma condição de estresse afetivo:

Imagine que você acabou de passar por uma cirurgia e ficará por algum tempo no hospital até estar pronto(a) para voltar para casa. Agora, imagine que você esteja se sentindo desanimado(a), cansado(a), com medo, nervoso(a), tímido(a), de mau humor, triste. 
Após alguns instantes, o quadro magnético com as fotografias foi apresentado ao paciente com a seguinte instrução:

Agora observe as fotografias. Todas elas mostram quartos de hospitais. Em que quartos você acha que poderia voltar a se sentir feliz, de bom humor, animado(a), cheio de energia e imaginação, relaxado(a) e calmo(a)? Você pode escolher quantas fotografias quiser, movendo as imagens para a parte de baixo do quadro.

Figura 1. Fotografias de quartos de internação utilizadas durante a entrevista.
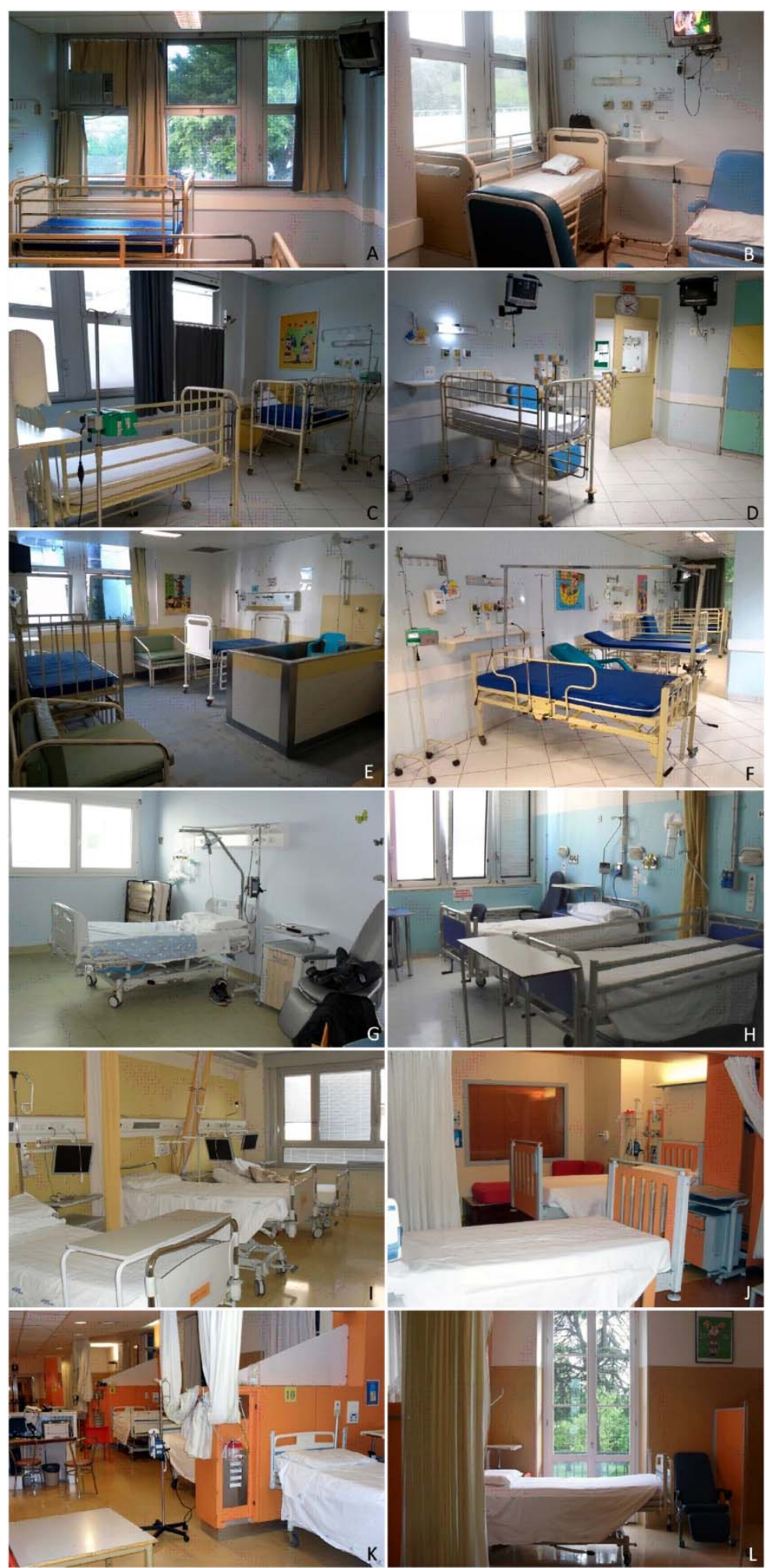

Fonte: Capturas fotográficas realizadas pela primeira autora; arquivos de pesquisa. 
Com essa questão, o paciente poderia refletir acerca da probabilidade percebida de restauração proporcionada pelos diferentes ambientes representados nas fotografias, sendo possível assim identificar aqueles percebidos como restauradores. Os estados afetivos descritos foram retirados da Lista de Estados de Ânimo - LEA (VOLP, 2000). A entrevista prosseguiu com a seguinte questão, que propõe uma elaboração a partir da pergunta anterior, estabelecendo-se assim uma ordem de importância entre os ambientes no que diz respeito ao bem-estar que proporcionam:

\begin{abstract}
Agora, coloque em ordem as fotografias que você escolheu de acordo com o sentimento de bem-estar que os quartos provocam em você. Coloque o quarto que causa maior bem-estar em primeiro lugar e vá organizando as imagens até chegar ao quarto que causa menor bem-estar, que será o último.
\end{abstract}

As duas primeiras questões da entrevista correspondem a técnicas fotográficas de investigação denominadas, respectivamente, classificação e ordenamento de fotografias (CAVALCANTE; MACIEL, 2008). Na sequência, propôs-se a pergunta: "Se você fosse contar a sua mãe (ou a algum familiar que estivesse presente) sobre como esse(s) quarto(s) que você escolheu é(são), o que você falaria?". Com esta questão, foi possível examinar as mensagens comunicadas pelos quartos de internação percebidos como restauradores. Alternativamente, caso o respondente não se expressasse em termos de significados ambientais, propunha-se a seguinte questão: "Diga as palavras que lhe vêm à cabeça quando você observa os quartos que escolheu".

Fez-se nota de todos os significados ambientais citados pelo paciente, de modo a se encerrar a entrevista com a pergunta: "Você disse que o(s) quarto(s) é(são): (inserção do significado ambiental citado pelo respondente). Que características físicas desse(s) quarto(s) fazem com que seja(m) assim?" Fez-se esta pergunta para cada significado que o paciente atribuiu aos ambientes representados nas imagens. Exemplo: "Você disse que os quartos são confortáveis. Que características físicas desses quartos fazem com que eles sejam assim?" A partir destas últimas questões, foi possível estabelecer uma correspondência entre as mensagens ambientais suscitadas pelos quartos percebidos como restauradores e os atributos físicos visuais que as geraram.

Os dados obtidos por meio das técnicas de classificação e ordenamento de fotografias, bem como as respostas relativas aos significados atribuídos pelos pacientes aos quartos de internação foram registrados pelos pesquisadores, no momento da entrevista, em uma planilha de anotações, onde também foram anotados dados para a caracterização dos respondentes, como sexo e data de nascimento. Toda a entrevista foi gravada por meio de aparelho de áudio digital.

\title{
Procedimentos
}

Nas primeiras visitas dos pesquisadores ao hospital, fotografias dos quartos das diferentes unidades de internação foram feitas. Parte dessas imagens foi utilizada posteriormente nas entrevistas. Para a coleta de dados junto às crianças e adolescentes, um elenco de pacientes que satisfaziam os critérios de inclusão foi previamente fornecido pela equipe de enfermagem nas diferentes unidades. No quarto de internação, cada família foi então abordada pelos pesquisadores, que forneceram oralmente ao paciente e aos pais ou responsáveis uma descrição do estudo. Um Termo de Consentimento Livre e Esclarecido e um Termo de Assentimento foram propostos aos responsáveis e ao paciente, respectivamente.

O paciente respondeu à entrevista deitado ou sentado sobre o leito. Um pesquisador sustentou verticalmente o quadro magnético com as fotografias à frente do participante enquanto fazia as perguntas. O respondente não foi informado sobre a origem das imagens (instituição ou país de pertencimento). Cada entrevista durou cerca de 10 minutos. Para evitar a transmissão de patologias, todo o material de pesquisa foi higienizado com álcool em gel 70 graus, antes e após cada utilização.

As entrevistas gravadas por meio de aparelho de áudio foram transcritas em meio digital e analisadas segundo análise de conteúdo temático categorial, como proposto por Bardin (1977). Já os dados da classificação e do ordenamento de fotografias anotados em planilha e aqueles para a caracterização dos participantes foram tabulados e submetidos à análise estatística descritiva e relacional com auxílio do programa Statistical Package for Social Sciences (SPSS). 
Felippe, M.; Hodecker, M.; Pichetti, D.; Kuhnen, A.

\section{RESULTADOS}

Participaram das entrevistas 50 pacientes, dos quais, 26 do sexo masculino. A média de idade foi 12 anos e 2 meses $(D P=2$ anos e 1 mês), sendo a idade mínima de 8 anos e 1 mês e a máxima de 15 anos e 8 meses.

\section{Classificação e ordenamento de fotografias}

Na primeira questão da entrevista, os participantes indicaram dentre as fotografias apresentadas aquelas que representavam quartos de internação percebidos como restauradores. Os quartos de internação mais indicados como restauradores foram o J (30 citações), L (24 citações), K (15 citações), B (13 citações), I (13 citações) e A (11 citações), sendo responsáveis por $84,80 \%$ do total de 125 citações. Cada um dos demais quartos foram apontados por 8 ou menos participantes (15,20\% das citações). O quarto C não foi mencionado em nenhuma das respostas à questão. O gráfico da Figura 2 apresenta as frequências absoluta e relativa de citação de cada quarto, obtidas por meio da técnica de classificação de fotografias.

Figura 2. Resultados da classificação e ordenamento das fotografias.

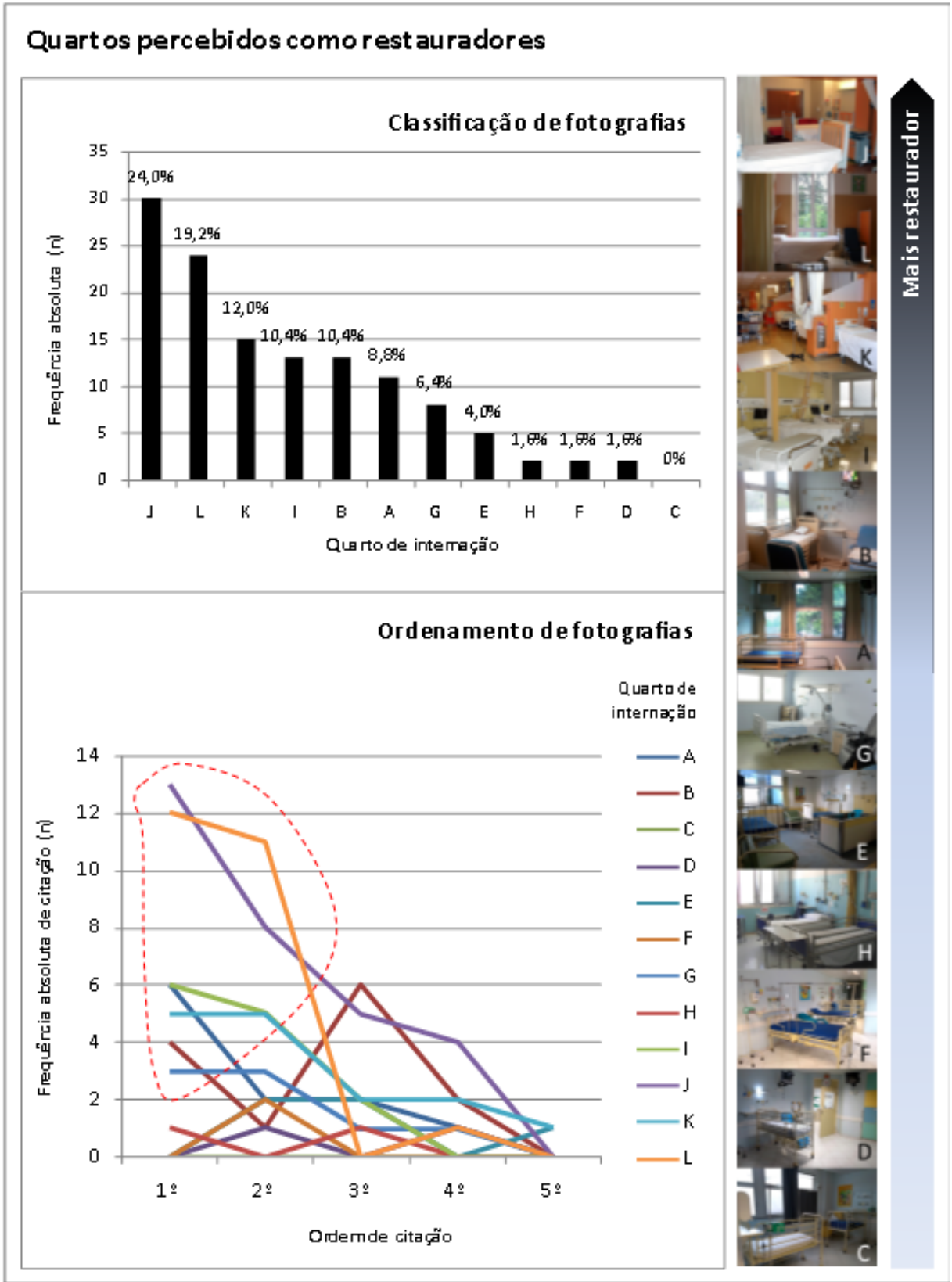

Fonte: Elaborado pela primeira autora. 
$\mathrm{O} x^{2}$ de uma variável ou teste de aderência foi executado com o objetivo de avaliar se as frequências de citação observadas diferiram significativamente daquelas que poderiam ser esperadas caso não houvesse diferenças entre os quartos quanto à probabilidade percebida de restauração, ou seja, caso todos quartos fossem igualmente percebidos como restauradores. O valor de $X^{2}$ de 42,87 com grau de liberdade 7 e probabilidade associada menor que 0,001 foi encontrado, indicando que existe uma diferença estatisticamente significativa entre as frequências observadas e esperadas: ou seja, os quartos de internação apresentados não são igualmente percebidos como restauradores pelos pacientes. Mais participantes consideraram restauradores os ambientes representados nas fotografias $\mathrm{J}$ e $\mathrm{L}$ em detrimento dos demais ambientes.

Posteriormente, na segunda questão, cada participante foi convidado a ordenar os ambientes selecionados, de acordo com o bem-estar que proporcionavam, colocando em primeiro lugar o quarto que suscitava maior bem-estar. Os dados obtidos por meio do ordenamento de fotografias confirmaram os resultados alcançados através da técnica de classificação: os quartos $\mathrm{J}$ e $\mathrm{L}$ foram os mais citados na primeira e na segunda posição do ordenamento, estando entre os mais restauradores segundo a percepção dos respondentes. O segundo gráfico da Figura 2 ilustra a frequência absoluta de citação das imagens em cada uma das posições do ordenamento fotográfico. A linha vermelha pontilhada evidencia a região correspondente ao maior número de citações nas primeiras posições. Como é possível observar, essa porção do gráfico é ocupada com maior ressalto pelos dois ambientes acima citados, destacando-se também os quartos $A, B, G$, I e K.

A partir dos dados do ordenamento de fotografias, foi possível construir uma escala envolvendo os 12 ambientes apresentados, do mais restaurador ao menos restaurador, segundo a percepção dos pacientes. Para tal, as frequências de citação das fotografias foram ponderadas de acordo com a posição no ordenamento, desta forma: citações na primeira posição receberam um peso maior (peso 12) que as citações na segunda posição (peso 11); citações na segunda posição receberam um peso maior que as citações na terceira posição (peso 10), e assim por diante. O somatório das frequências ponderadas determinou a posição de cada fotografia, de modo que as fotografias com o maior número de citações nas primeiras posições ocuparam os primeiros postos da escala, que pode ser consultada no canto direito da Figura 2. A ordem das imagens coincidiu com a sequência de fotografias por frequência de citação segundo a técnica de classificação, o que atesta alta congruência entre os resultados dos instrumentos.

\section{Significados ambientais}

As respostas às demais questões da entrevista permitiram a extração dos significados atribuídos pelos pacientes aos quartos percebidos por eles como restauradores. A análise de conteúdo das respostas identificou 27 elementos temáticos diferentes (significados ambientais). Os elementos temáticos mais presentes foram "confortável" (19 presenças), "bonito" (15 presenças), "legal" (14 presenças), "bom" (13 presenças), "colorido" (12 presenças), "espaçoso" (9 presenças), "tranquilo" (9 presenças) e "alegre" (7 presenças), indicados por sete ou mais pacientes cada um. Juntos, estes elementos foram responsáveis por 168 ocorrências $(75,67 \%)$.

Estes elementos foram agrupados por semelhança em categorias de mesma natureza semântica. As categorias da pesquisa de Felippe (2015) foram tomadas como referência para o presente estudo, como parte do trabalho de investigação das similaridades e diferenças entre os dois trabalhos. Assim, os 27 elementos temáticos foram organizados em cinco categorias semânticas. Dessa forma, foi possível inferir que os pacientes perceberam os quartos de internação com potencial restaurador como ambientes: (a) confortáveis, equipados, cuidados, onde se está bem e se tem controle sobre variáveis ambientais, sendo esta a categoria que reuniu mais da metade do total de ocorrências (62,16\% das ocorrências); (b) alegres, interessantes (13,96\% das ocorrências); (c) bonitos (11,26\% das ocorrências); (d) tranquilos e relaxantes (10,36\% das ocorrências); e, por fim, (e) reconfortantes, que fazem sentir-se protegido (2,25\% das ocorrências).

\section{Atributos físicos que suscitam os significados ambientais ligados à restauração}

A análise dos atributos físicos que suscitam os significados ambientais ligados à restauração foi realizada para cada uma das categorias de significados. Os dados completos da análise de conteúdo podem ser consultados em Felippe (2019). Por meio da síntese temática realizada, foi possível inferir que, tipicamente, para os participantes da pesquisa, um quarto de internação confortável possui móveis essenciais e de apoio 
adequados, incluindo aqueles para os acompanhantes; possui janelas que oferecem possibilidade de contato com o exterior, especialmente com a natureza; tem, além do branco, cores vivazes, como o amarelo e o laranja; é equipado com TV; tem amplas dimensões; e oferece bom atendimento. Já os atributos físicos que tornam alegres e interessantes os quartos de internação estão ligados a cores diversas, entre elas, o laranja e o azul; além disso, móveis diferentes do usual, como é o caso das camas com proteções laterais em madeira. Observou-se adicionalmente que, um quarto de internação bonito é tipicamente colorido, em especial nos tons de laranja; aparenta boa organização; e possui janelas que oferecem possibilidade de contato com o exterior, especialmente com a natureza. Esta última também é uma característica de quartos tranquilos e relaxantes, bem como daqueles reconfortantes, que fazem sentir-se seguro.

\section{DISCUSSÃO}

Essa discussão abrange três tópicos: (i) ambientes percebidos como restauradores; (ii) significados ambientais de locais percebidos como restauradores; (iii) atributos físicos que suscitam os significados ambientais ligados à restauração.

\section{Ambientes percebidos como restauradores}

Os resultados encontrados pela análise dos dados obtidos nas diferentes técnicas foram congruentes. A sequência de imagens restauradoras por frequência de citação a partir da técnica de classificação e de ordenamento de fotografias coincidiu, tendo sido possível formar uma escala sequencial de ambientes que promovem maior e menor bem-estar. Adicionalmente, o teste de aderência indicou que os diversos ambientes não foram igualmente percebidos como restauradores pelos pacientes, que consideraram mais vezes em suas escolhas os quartos $\mathrm{J}$ e $\mathrm{L}$, em detrimento dos demais. Esse resultado dá significado à hierarquia sequencial de imagens formada, estabelecendo-se uma ordem de importância entre os ambientes no que diz respeito ao bem-estar que proporcionam.

A fim de comparar os resultados do presente estudo àqueles encontrados em estudo similar desenvolvido na Itália (FELIPPE, 2015), alguns paralelos serão traçados. Na investigação italiana, foi possível registrar a restauração afetiva de pacientes pediátricos a partir de uma condição de estresse (procedimento cirúrgico) e relacionar tal restauração às características físicas dos quartos ocupados pelos pacientes investigados. Resultados dessa análise indicaram que a restauração afetiva foi maior quanto maior foi a área total de aberturas voltadas para o exterior e a área de aberturas envidraçadas. Além disso, a recuperação a partir do estresse covariou negativamente com o peitoril de janelas, tendo sido maior quanto menor foi o valor do peitoril. A investigação ainda identificou outra relação estatisticamente significativa: a mediana dos escores de restauração afetiva foi maior quando havia a presença de divisórias entre os leitos em quartos múltiplos, se comparada àquela observada nos quartos sem divisórias.

No presente estudo, os ambientes mais frequentemente percebidos como restauradores, a partir das técnicas fotográficas, trazem características físicas semelhantes àquelas encontradas no estudo de Felippe (2015). As quatro primeiras imagens representam ambientes de internação com divisórias entre leitos (todas as demais, à exceção de uma fotografia, mostram ambientes com múltiplos leitos sem as divisórias). Outra semelhança entre os estudos diz respeito ao peitoril de janela e a abertura para o espaço externo. Dentre todas as imagens, aquela que apresenta uma janela com o peitoril mais baixo, valorizando a área envidraçada voltada ao exterior, atingiu segunda posição na escala de bem-estar, estando entre as mais frequentemente escolhidas pelos participantes.

No estudo italiano, em uma segunda fase de investigação, também foram realizadas entrevistas com pacientes pediátricos a partir de fotografias de quartos de internação. O objetivo foi identificar características físicas ambientais que suscitavam mensagens relacionadas à restauração afetiva do estresse. Assim, pediu-se aos pacientes que classificassem e ordenassem fotografias de ambientes segundo a mensagem que comunicavam (belo, tranquilo, cômodo, alegre e reconfortante) identificando, por fim, as características ambientais relevantes na comunicação desses significados. Uma análise conjunta dos resultados dessa fase do estudo revelou que três dos onze quartos apresentados em fotografias estiveram mais frequentemente nas primeiras posições de citação, tendo sido mais vezes lembrados pelos pacientes como ambientes que melhor comunicam todas as mensagens ambientais investigadas no estudo (ver Figura 3).

Como é possível perceber, dois dos ambientes representados na referida figura foram também utilizados no presente estudo e correspondem aos quartos $\mathrm{J}$ e $\mathrm{L}$ (imagem da esquerda e do centro da Figura 3 , respectivamente), ou seja, os quartos mais vezes percebidos pelos participantes brasileiros como ambientes capazes de restaurar a partir de uma condição de estresse. Pacientes de ambos os países 
mencionaram esses dois quartos mais vezes que os demais em suas respostas à classificação e ao ordenamento de fotografias. Na mesma direção, os demais quartos comuns aos dois estudos (G, H, I, K, ) também obtiveram posições semelhantes na classificação geral de citações: o ambiente identificado no estudo brasileiro como $\mathrm{H}$ esteve nas últimas colocações de citação em ambos os estudos; enquanto que os quartos G, I e K obtiveram posições intermediárias, tanto na Itália, quanto no Brasil.

Observando-se a sequência de imagens formada a partir dos dados obtidos pelas técnicas fotográficas (ver Figura 2), notam-se ao menos quatro aspectos físicos relevantes nas fotografias que ocupam as primeiras posições: cores quentes (vermelho, laranja e amarelo); móveis diferentes dos usualmente encontrados em hospitais; valorização da abertura ao exterior com possibilidade de vista para a natureza; e presença de divisórias (cortinas ou divisórias fixas) entre leitos, em quartos múltiplos. Cada uma das seis primeiras imagens da escala de fotografias tem ao menos uma dessas características, sendo que as quatro primeiras são dotadas de, no mínimo, dois desses atributos físicos (as fotografias $\mathrm{J}$ e $\mathrm{L}$, as mais citadas, têm três desses atributos).

Figura 3. Fotografias mais frequentemente citadas no estudo de Felippe (2015).

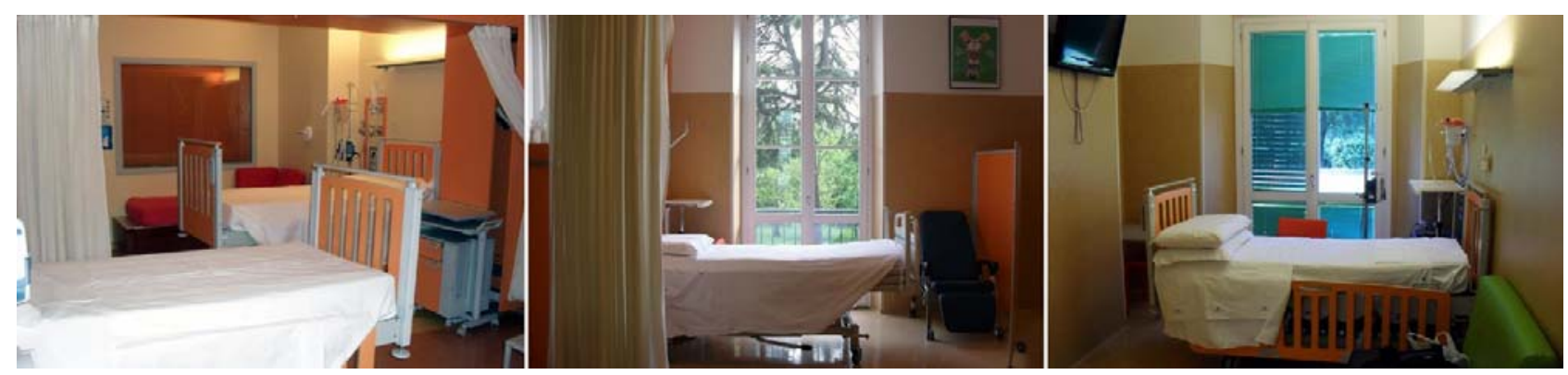

Fonte: Recuperado de Felippe (2015).

Cores vivazes, particularmente nos tons alaranjados, amarelos e avermelhados; cortinas; e móveis com um desenho inusual - como os leitos com estrutura lateral em madeira - foram características associadas, no estudo italiano (FELIPPE, 2015), a um aspecto residencial do ambiente hospitalar. Atributos físicos que resultaram em uma aparência residencial estiveram associados, naquele estudo, a todos os significados ambientais ligados à restauração. Quando atributos físicos que resultam em uma aparência residencial são percebidos em um ambiente, um sentido de proteção, segurança, confiança, intimidade, tranquilidade e repouso pode ser evocado (FELIPPE, 2010).

As cortinas, além do aspecto residencial, também oferecem a oportunidade de maior privacidade no ambiente hospitalar. A privacidade é uma forma de regulação das interações sociais a fim de adequá-las às necessidades pessoais (VALERA; VIDAL, 2000). Como tal, é uma dimensão ambiental que pode afetar a saúde humana por alteração dos níveis de estresse (ULRICH, 1991). A falta de controle sobre a privacidade pode ser estressante, da mesma forma que uma maior percepção de controle sobre as interações sociais proporciona conforto emocional (WILLIAMS; IRURITA, 2005).

Outro aspecto que parece ser relevante nas imagens mais escolhidas pelos pacientes é a valorização da abertura para o exterior, em especial, para a natureza. Pesquisas em ambientes hospitalares e não hospitalares, com adultos e crianças, têm demonstrado os efeitos restauradores do contato com a natureza, seja por meio de janelas (ULRICH, 1984; WALCH et al., 2005), acesso a jardins (SAID et al., 2005), parques (VAN DEN BERG et al., 2010) e florestas (TSUNETSUGU et al., 2013), ou na presença de plantas de interior (PARK; MATTSON, 2009) e fotografias (DIETTE et al., 2003); ou ainda através de vídeos (ULRICH et al., 1991) e estímulos sonoros (DIETTE et al., 2003). Além de atuar sobre a restauração da saúde, o contato com a natureza no ambiente hospitalar também tem sido associado à redução de depressão, maior satisfação, menor tempo de internação, menos dor e melhor sono (ULRICH et al., 2008).

As experiências de restauração passadas atuam sobre a preferência ambiental (VAN DEN BERG et al., 2003). Como mecanismo autorregulatório, esta teria a função de incentivar a aproximação do indivíduo a contextos ambientais que satisfazem suas necessidades e exigências biopsicossociais, fato que pode explicar a escolha por parte dos pacientes de imagens com conteúdo relativo à natureza.

\section{Significados ambientais de locais percebidos como restauradores}

Após a seleção de imagens representativas de quartos percebidos como restauradores, os pacientes participantes da pesquisa puderam informar acerca dos significados que associavam a esses ambientes. A análise de conteúdo identificou que os pacientes perceberam tipicamente os quartos como confortáveis, 
equipados, cuidados, onde se está bem e se tem controle sobre variáveis ambientais. Outros significados estiveram também associados aos ambientes, porém, com menor frequência. São eles: quartos alegres, interessantes; bonitos; tranquilos e relaxantes; e, por fim, reconfortantes, que fazem sentir-se protegido.

A categorização utilizada baseou-se no estudo de Felippe (2015, p. 101). Na referida investigação, pacientes que haviam manifestado restauração $(\mathrm{N}=43)$ durante o período de internação hospitalar, a partir de uma condição de estresse afetivo, descreveram o próprio quarto de hospital em termos dos significados comunicados. Cinco classes de significados emergiram: (a) alegre, vivaz, interessante e divertido; (b) calmo, tranquilo e relaxante; (c) confortável, acolhedor, onde se está bem, à vontade, onde as pessoas se sentem livres, não oprimidas; (d) reconfortante, onde as pessoas se sentem protegidas, amadas; e (e) bonito. Com exceção da categoria "bonito", todas as demais correspondem a significados que, no estudo italiano, estiveram estatisticamente relacionados ao processo de restauração. Pequenas adaptações de categorização foram feitas, do estudo italiano para o brasileiro, em razão do conteúdo de respostas revelado na análise do estudo mais recente. Na Tabela 1 observa-se a comparação entre as nomenclaturas utilizadas nas duas investigações e a palavra síntese que representa cada par de categorias.

Todos os elementos temáticos identificados na análise de conteúdo do estudo brasileiro puderam ser categorizados adotando-se como referência o critério de classificação formulado no estudo anterior. Isso porque os elementos temáticos presentes em ambas as investigações se assemelham e, portanto, não sugerem alterações significativas quanto à nomenclatura das classes semânticas que os representam. É possível dizer, dessa forma, que os pacientes de ambas as amostras se expressaram de modo similar ao dotarem de significado ambientes relevantes no processo de restauração.

Tabela 1. Nomenclaturas de classes de significados no estudo italiano e brasileiro

\begin{tabular}{|c|c|c|}
\hline \multirow{2}{*}{$\begin{array}{l}\text { Palavra } \\
\text { síntese }\end{array}$} & \multicolumn{2}{|l|}{ Classes de significados } \\
\hline & Estudo italiano & Estudo brasileiro \\
\hline Alegre & Alegre, vivaz, interessante e divertido & Alegre, interessante \\
\hline Tranquilo & Calmo, tranquilo e relaxante & Tranquilo, relaxante \\
\hline Confortável & $\begin{array}{l}\text { Confortável, acolhedor, onde se está bem, à vontade, onde } \\
\text { as pessoas se sentem livres, não oprimidas }\end{array}$ & $\begin{array}{l}\text { Confortável, equipado, cuidado, onde se está bem e se } \\
\text { tem controle sobre variáveis ambientais }\end{array}$ \\
\hline Reconfortante & $\begin{array}{l}\text { Reconfortante, onde as pessoas se sentem protegidas, } \\
\text { amadas }\end{array}$ & Reconfortante, que faze sentir-se protegido \\
\hline Bonito & Bonito & Bonito \\
\hline
\end{tabular}

A diferença fundamental, no entanto, entre os resultados dos dois estudos diz respeito à proporção de citações em cada categoria. Conforme é possível verificar na Figura 4, o percentual de citações na categoria "confortável" foi mais expressivo no estudo brasileiro. Em compensação, as citações nas categorias "reconfortante", "tranquilo" e "alegre" diminuíram notavelmente. Essas diferenças podem em parte ser explicadas pelo fato de que apenas uma porção dos quartos de internação avaliados são comuns aos dois estudos. Outras razões podem estar ligadas aos interesses e necessidades próprias de cada amostra.

Para as crianças e adolescentes de ambos os estudos, aspectos funcionais do ambiente foram priorizados em detrimento de aspectos estéticos, assim como discutiu Said (2007). A questão da beleza dos ambientes, embora presente nos discursos dos pacientes, constituiu categoria de significados dentre os menos recorrentes. Em contrapartida, aspectos ligados ao conforto, diversão e alegria foram frequentes. Nota-se aí tanto a presença de significados ligados diretamente à experiência de hospitalização - na qual é importante haver a possibilidade de estar em lugares confortáveis, compatíveis com a condição de repouso e a vulnerabilidade envolvida no período de internação - como de significados ligados aos interesses próprios da fase de desenvolvimento de crianças e adolescentes - na qual o jogo, a diversão, o entretenimento e a liberdade de ir e vir assumem um papel importante como mecanismos autorreguladores de estimulação física e social.

De acordo com Tuan (1980), o processo perceptivo se dá a partir da seleção de estímulos ambientais disponíveis - ou seja, da escolha do que é percebido - em razão dos interesses e das disposições do observador. Portanto, podemos considerar que o grupo de qualidades ambientais que surgiram como significados atribuídos aos quartos de internação reflete os interesses dos participantes do presente estudo, ou seja, os aspectos do ambiente que são importantes para eles. Esses aspectos ambientais podem diferir 
daqueles privilegiados por adultos (SAID, 2007), por exemplo, especialmente se considerarmos que a percepção ambiental atende as necessidades próprias do processo evolutivo: ela tem um papel decisivo no desenvolvimento e funcionamento humanos, porque se estende em modos de interação ambiental específicos para a fase do desenvolvimento que o indivíduo atravessa. Ou seja, o modo como a criança percebe é também uma função de suas necessidades de interação com o ambiente - por exemplo, responder imediatamente às fontes de estimulação ambiental e agir em modo caracteristicamente exploratório (SAID, 2007) - com impacto sobre o seu desenvolvimento.

Figura 4. Ocorrência de citação por significado ambiental no estudo italiano e brasileiro.

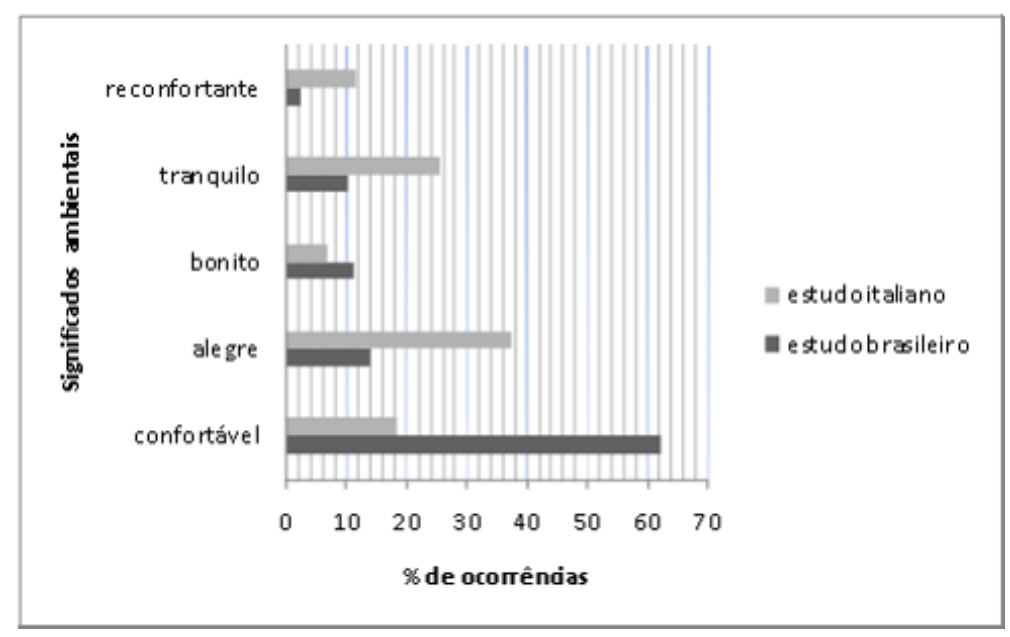

Fonte: Elaborado pela primeira autora.

\section{Atributos físicos que suscitam os significados ambientais ligados à restauração}

Uma vez encontrados os significados que ambientes percebidos como restauradores comunicam, procedeu-se a uma fase de investigação para a identificação dos atributos físicos ambientais que eliciam tais significados. Comparando-se os achados do presente estudo com aqueles da investigação realizada na Itália (FELIPPE, 2015), nota-se que, para cada significado ambiental estudado, todas as categorias temáticas relativas a atributos físicos do estudo brasileiro estão contidas nos resultados do estudo italiano, tendo, no primeiro caso, a distribuição de citações se concentrado em um número menor de categorias. A Figura 5 ilustra a comparação.

Além disso, para cada significado ambiental investigado, todas as categorias temáticas que superaram o número de citações estatisticamente esperadas no estudo brasileiro, também superaram o número de citações esperadas no estudo italiano, com uma exceção: para o significado ambiental "reconfortante", a categoria temática "aberturas ao exterior" superou o número de citações estatisticamente esperadas no estudo brasileiro, mas não no italiano. Na Figura 5 , as categorias com citações observadas superiores às esperadas foram destacadas em vermelho. Desse modo, é possível dizer que, em comum, os dois estudos apontam como relevantes as seguintes categorias de atributos físicos por significado ambiental:

- Quartos bonitos: cores; móveis, equipamentos e complementos; aberturas ao exterior;

- Quartos confortáveis: móveis, equipamentos e complementos; aberturas ao exterior;

- Quartos tranquilos: aberturas ao exterior;

- Quartos alegres: cores;

- Quartos reconfortantes: móveis.

No estudo italiano, para os significados ambientais "confortável", "alegre", "tranquilo" e "reconfortante", também é possível observar outras categorias de atributos físicos relevantes (marcadas em vermelho na Figura 5). Na investigação brasileira, a partir de uma análise de conteúdo conjunta das respostas dadas às entrevistas, foi possível sistematizar os atributos físicos nas seis qualidades ambientais listadas a seguir:

- Mobiliário adequado, o que inclui cama confortável, mesa de apoio e móveis apropriados destinados aos acompanhantes; 
- Ambiente colorido, particularmente dotado de cores vivazes, como o laranja, vermelho e amarelo;

- Acesso visual ao ambiente exterior, particularmente ao ambiente natural;

- Acesso a equipamentos que podem oferecer distração positiva, como a TV;

- Amplitude;

- Organização e ordem da estrutura hospitalar.

Figura 5. Frequência relativa de citação (\%) de atributos físicos por categoria temática, para cada significado ambiental estudado no Brasil e na Itália.

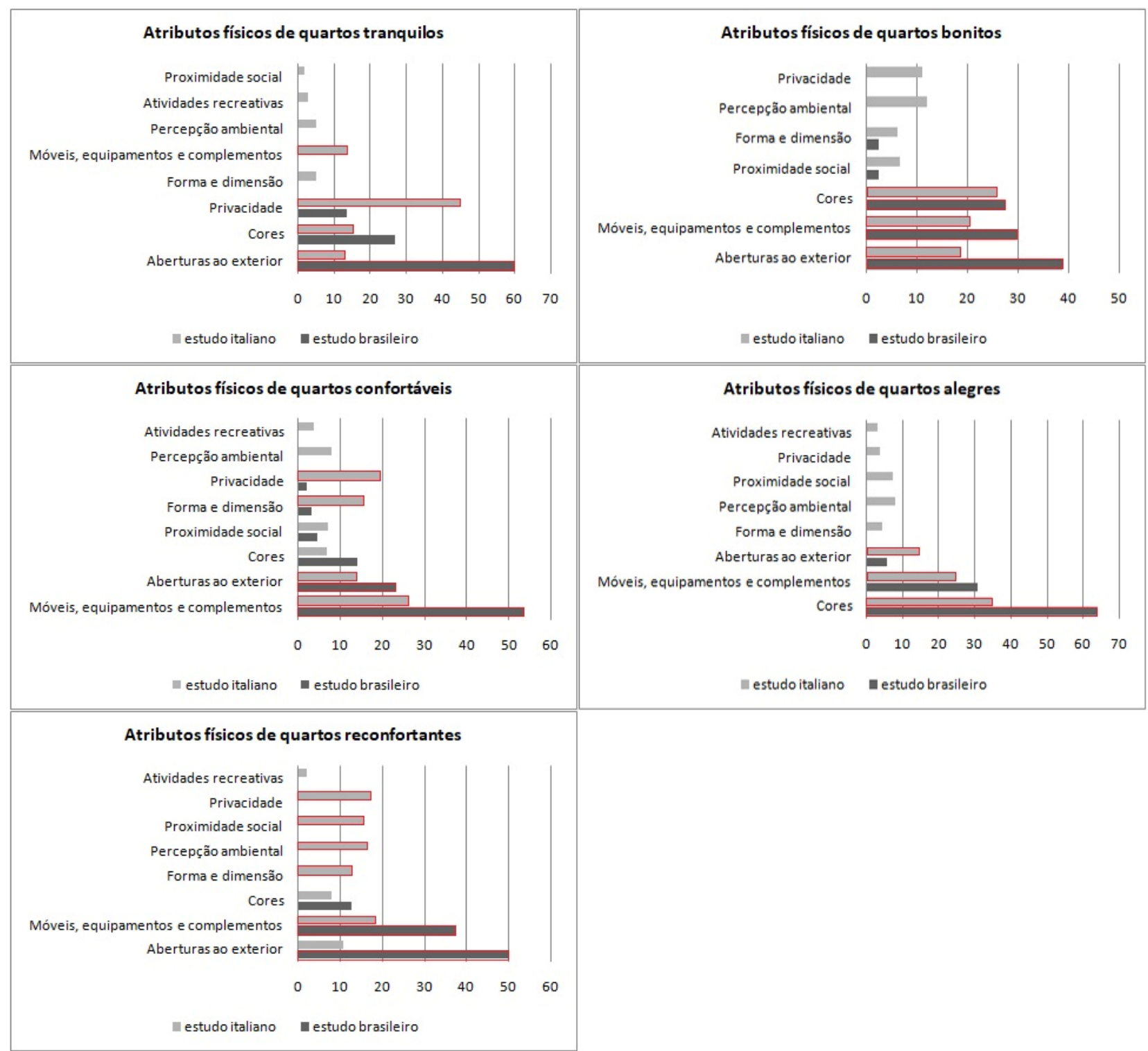

Fonte: Elaborado pela primeira autora.

O conjunto de atributos físicos identificados neste estudo como características que suscitam significados ligados a quartos percebidos como restauradores vão ao encontro de qualidades ambientais relatadas na literatura como aspectos físicos que suportam a experiência positiva de crianças e adolescentes em hospitais (BISHOP, 2008). Todos eles estão contidos na lista de atributos físicos que comunicam mensagens ambientais relacionadas à restauração afetiva do estresse no estudo de Felippe (2015), podendo ser considerados resultados comuns entre as amostras brasileira e italiana.

As características presentes no estudo italiano que não receberam o mesmo destaque no discurso dos pacientes participantes da presente investigação dizem respeito a: (a) oportunidade de privacidade e de (b) interação social; (c) quadros e ilustrações nas paredes; e (d) presença de brinquedos e áreas para jogos.

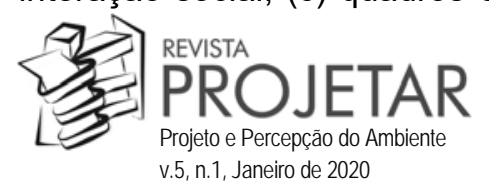


Todavia, todos esses aspectos compareceram no discurso dos pacientes brasileiros, apenas em frequência inferior àquela que poderia ser estatisticamente esperada dentro da categoria de significado ambiental a que pertenciam.

Além disso, alguns desses atributos físicos, especificamente aqueles que oferecem oportunidade para a privacidade (como cortinas e divisórias entre leitos), podem ser notados nas imagens escolhidas pelos pacientes como mais restauradoras.

\section{CONCLUSÃO}

Este estudo buscou identificar atributos físicos visuais de quartos de internação pediátricos que comunicam aos pacientes mensagens ambientais ligadas ao processo de restauração afetiva do estresse. Para tanto, identificou inicialmente quartos percebidos pelos pacientes como ambientes restauradores e examinou as mensagens comunicadas por eles. Encontrou que esses quartos foram percebidos caracteristicamente como lugares confortáveis, equipados, cuidados, onde se está bem e se tem controle sobre variáveis ambientais; mas também como ambientes alegres, interessantes; bonitos; tranquilos e relaxantes; e, por fim, ambientes reconfortantes, que fazem sentir-se protegido.

Ao final do procedimento investigativo, ao se estabelecer uma correspondência entre esses significados ambientais e os atributos físicos visuais que os geram, este estudo concluiu que as seguintes características do quarto de internação desempenham um papel na comunicação de mensagens ligadas ao processo restaurador: (a) mobiliário adequado, incluindo cama confortável, mesa de apoio e móveis apropriados destinados aos acompanhantes; (b) ambiente colorido, particularmente dotado de cores vivazes, como o laranja, vermelho e amarelo; (c) acesso visual ao ambiente exterior, particularmente ao ambiente natural; (d) acesso a equipamentos que podem oferecer distração positiva, como a TV; (e) amplitude; e (f) organização e ordem da estrutura hospitalar.

Com o objetivo de comparar esses resultados com aqueles já obtidos em um contexto cultural diferente, traçou-se um paralelo entre a presente investigação e um estudo anterior realizado pelo primeiro autor em quatro hospitais italianos (de Florença, Pádua, Bolonha e Ferrara). Diversas similaridades foram encontradas, entre elas:

- As fotografias comuns aos dois estudos, utilizadas nas entrevistas, obtiveram posições semelhantes na classificação geral de citações, de modo que quartos mais e menos vezes mencionados pelos participantes coincidiram nos resultados obtidos na Itália e no Brasil;

- Os pacientes de ambas as amostras se expressaram de modo similar ao dotarem de significado ambientes relevantes no processo de restauração. Os elementos temáticos identificados na análise de ambas as investigações se assemelharam e, portanto, puderam ser categorizados adotando-se a mesma classificação;

- Para cada significado ambiental estudado, todas as categorias temáticas relativas a atributos físicos associados, no estudo brasileiro, estão contidas nos resultados do estudo italiano; além disso, as categorias que superaram o número de citações estatisticamente esperadas no Brasil caracteristicamente também superaram o número de citações esperadas na Itália;

- Os atributos físicos identificados no presente estudo como relevantes na comunicação de significados ambientais ligados ao processo restaurador estão contidos inteiramente na lista de atributos físicos do estudo realizado na Itália, podendo ser considerados resultados comuns entre as duas amostras.

Em outras palavras, pacientes italianos e brasileiros atribuem os mesmos significados a quartos restauradores (no caso italiano) ou percebidos como restauradores (no caso brasileiro): eles são ambientes confortáveis, alegres, bonitos, tranquilos e reconfortantes. Além disso, existe um núcleo comum aos dois estudos no que diz respeito aos atributos físicos relevantes neste processo de significação. Este núcleo é, em síntese, representado pelas seguintes características: ambiente amplo; colorido; em ordem e organizado; com mobiliário adequado; acesso a TV e ao ambiente exterior, particularmente natural. De modo mais específico, comparando-se os dois estudos, é possível perceber que "cores" são elementos importantes na produção de espaços percebidos como alegres e bonitos; "aberturas ao exterior" são relevantes para a percepção de tranquilidade, beleza e conforto; enquanto que "móveis" podem atuar na construção de ambientes confortáveis, bonitos e reconfortantes.

Apesar das similaridades, nota-se, em essência, uma diferença fundamental entre as duas investigações, particularmente no que diz respeito ao exame de atributos físicos ambientais: os resultados do estudo brasileiro estão contidos naqueles obtidos na Itália, não sendo verdadeira a relação de direção contrária. Os 
achados da investigação italiana avançaram por mais temas que aqueles encontrados no Brasil e o motivo pode estar relacionado ao fato de que, na Itália, uma amostra maior de pacientes foi estudada (69 em uma primeira fase, 55 em uma segunda fase) e mais hospitais participaram do estudo, hospitais estes pertencentes a três regiões geográficas diferentes (Florença, Veneto, Emília-Romanha). Uma maior amplitude amostral pode ter sido responsável por introduzir uma maior variedade de elementos de pesquisa, identificando-se, no entanto, um núcleo central comum a ambas as investigações.

Outra diferença entre os estudos diz respeito à atribuição de significado pelos pacientes aos quartos de internação. $O$ aspecto ligado ao conforto (quarto confortável) foi notadamente mais expressivo para a amostra no Brasil, em detrimento de outros significados, como "reconfortante", "tranquilo" e "alegre", indicando, por contraposição, que os participantes brasileiros podem ter como maior necessidade elementos que tornem a experiência no hospital mais cômoda e acolhedora.

É uma limitação do presente estudo o fato de ter investigado a probabilidade percebida de restauração a partir de um cenário hipotético de estresse afetivo. Esse método não é adequado para a avaliação da restauração de fato, ou seja, a restauração real, como no estudo italiano. Embora os resultados entre as duas investigações tenham convergido, há, no caso brasileiro, uma correspondência incerta entre os juízos de probabilidade e uma eventual real restauração. Adicionalmente, o uso da fotografia traz limitações no que diz respeito à capacidade das imagens de se sobreporem à realidade representada, ou seja, no presente estudo, não se pode compreender em que medida as fotografias utilizadas substituem ambientes reais na produção de respostas psicofisiológicas. Também o método da observação indireta por meio de inquérito traz a limitação de depender da vontade e da habilidade do participante em comunicar algo. Desse modo, sugere-se em novas pesquisas a utilização de medidas reais de restauração, inseridas em um plano de abordagem multimetodológica para confronto e complementação de dados.

Apesar das limitações de método, o instrumento de pesquisa mostrou-se interessante ao paciente, que pode manuseá-lo a partir do próprio leito de internação, movendo as peças imantadas sobre uma superfície metálica, em uma espécie de jogo lúdico. Além disso, a imagem fotográfica teve a vantagem de mediar a realidade, produzindo um vínculo entre o observador e o conteúdo observado que potencializou independentemente da habilidade escrita do respondente - depoimentos para além da imagem.

Fazendo a convergência entre dados, este estudo contribuiu para a identificação de aspectos comuns e diversos em pesquisas sobre atributos físicos e significados ambientais no processo de restauração em hospitais, colocando em ressalto elementos que podem ser de fato importantes na relação entre o paciente pediátrico e o ambiente hospitalar durante seu percurso de cura. Ao relacionar restauração afetiva e significados ambientais, e identificar atributos do ambiente hospitalar promotores de tais significados em crianças, pretendeu oferecer contribuições tanto ao campo do Design Baseado em Evidência, como aquele da hospitalização pediátrica, um setor com reconhecidos défices no campo de investigação da restauração do estresse.

\section{REFERÊNCIAS}

BARDIN, L. Análise de conteúdo. Lisboa: Edições 70, 1977.

BISHOP, K. G. From their perspectives: children and young people's experience of a paediatric hospital environment and its relationship to their feeling of well-being. Tese (Doutorado em Arquitetura), University of Sydney, Sydney, 2008. Disponível em: https://core.ac.uk/download/pdf/41232261.pdf. Acesso em: 11 set. 2019.

BONNES, M.; FORNARA, F.; BONAIUTO, M. Psicologia ambientale e architettura per la progettazione dei luoghi di cura. In: DEL NORD, R. (org.). L'ospedale del futuro: modelli per una nuova sanità. Padova: II Prato, 2008. p. 52-61.

CAVALCANTE, S.; MACIEL, R. H. Métodos de avaliação da percepção ambiental. In: PINHEIRO, J. Q.; GÜNTHER, H. (orgs.). Métodos de pesquisa nos estudos pessoa-ambiente. São Paulo: Casa do Psicólogo, 2008. p. 149-180.

DIETTE, G. B. et al. Distraction therapy with nature sights and sounds reduces pain during flexible bronchoscopya: a complementary approach to routine analgesia. Chest, v. 123, n. 3, p. 941-948, 2003. Disponível em: https://journal.chestnet.org/article/S0012-3692(16)34766-3/fulltext. Acesso em: 11 set. 2019.

FELIPPE, M. L. Casa: Uma poética da terceira pele. Psicologia e Sociedade, v. 22, n. 2, p. 299-308, 2010. Disponível em: http://www.scielo.br/scielo.php?pid=S0102-71822010000200010\&script=sci_abstract\&tlng=pt. Acesso em: 29 dez. 2019.

FELIPPE, M. L. Ambiente fisico e linguaggio ambientale nel processo di rigenerazione affettiva dallo stress in camere di degenza pediátrica. Tese (Doutorado em Tecnologia da Arquitetura), Università degli Studi di Ferrara, Ferrara, Itália, 2015. Disponível em: http://eprints.unife.it/994/. Acesso em: 29 dez. 2019. 
FELIPPE, M. L. et al. What is a restorative hospital environment? Environmental meaning, affective stress restoration and physical attributes in pediatric inpatient rooms. Children, Youth and Environments, v. 27, n. 1, p. 17-46, 2017. Disponível em: https://www.jstor.org/stable/10.7721/chilyoutenvi.27.1.0017?seq=1. Acesso em: 29 dez. 2019.

FELIPPE, M. L. Ambiente físico e significado ambiental no processo de restauração afetiva do estresse em quartos de internação pediátricos. Relatório de pesquisa (Pós-doutorado em Psicologia), Universidade Federal de Santa Catarina, Florianópolis, 2019.

FONTANELLA, B. J. B.; RICAS, J.; TURATO, E. R. Amostragem por saturação em pesquisas qualitativas em saúde: contribuições teóricas. Cadernos de Saúde Pública, v. 24, n. 1, p. 17-27, 2008. Disponível em: http://www.scielo.br/scielo.php?script=sci_arttext\&pid=S0102-311X2008000100003\&lng=pt\&tlng=pt. Acesso em: 11 set. 2019.

HARTIG, T. Issues in restorative environment research: matters of measurement. In: FERNÁNDEZ-RAMíREZ, B. et al. (orgs.). Psicología ambiental 2011: entre los estudios urbanos y el análisis de la sostenibilidad. Almería: Universidad de Almería, 2011. p. 41-66.

NEIVA-SILVA, L.; KOLLER, S. H. O uso da fotografia na pesquisa em psicologia. Estudos de Psicologia (Natal), v. 7, n. 2, p. 237-250, 2002. Disponível em: http://www.scielo.br/scielo.php?script=sci_arttext\&pid=S1413294X2002000200005\&lng=pt\&tIng=pt. Acesso em: 11 set. 2019.

RAPOPORT, A. The meaning of the built environment: a nonverbal communication approach. Tucson: University of Arizona, 1990.

SAID, I. Architecture for children: understanding children perception towards built environment. In: INTERNATIONAL CONFERENCE OF CHALLENGES AND EXPERIENCES IN DEVELOPING ARCHITECTURAL EDUCATION IN ASIA. Proceedings of ......Indonesia: Islamic University of Indonesia, 2007, p. 1-6. Disponível em: http://eprints.utm.my/3575/1/Architectural_EDU2.pdf. Acesso em: 11 set. 2019.

SAID, I. et al. Caregivers' evaluation on hospitalized children's preferences concerning garden and ward. Journal of Asian Architecture and Building Engineering, v. 4, n. 2, p. 331-338, 2005. Disponível em: https://www.tandfonline.com/doi/abs/10.3130/jaabe.4.331. Acesso em: 11 set. 2019.

SHUMAKER, S. A.; REIZENSTEIN, J. E. Environmental factors affecting inpatient stress in acute care hospitals. In: EVANS, G. W. Environmental stress. New York: Cambridge University Press, 1982. p. 179-223.

TUAN, Y.-F. Topofilia: um estudo de percepção, atitudes e valores do meio ambiente. São Paulo: Difel, 1980.

ULRICH R. S. Effects of healthcare environmental design on medical outcomes. In: DESIGN \& HEALTH WORLD CONGRESS \& EXHIBITION. Proceedings of the Second International Conference on Health and Design. Stockholm: IADH, 2001, p. 49-59. Disponível em https://www.brikbase.org/content/effects-healthcare-environmental-design-medicaloutcomes. Acesso em: 11 set. 2019.

ULRICH, R. S. Effects of interior design on wellness: theory and recent scientific research. Journal of Health Care Interior Design, v. 3, p. 97-109, 1991. Disponível em: https://www.ncbi.nlm.nih.gov/pubmed/10123973. Acesso em: 11 set. 2019.

ULRICH, R. S. et al. A review of the research literature on evidence-based healthcare design. HERD, v. 1, n. 3, p. 61125, 2008. Disponível em: https://journals.sagepub.com/doi/abs/10.1177/193758670800100306?journalCode=hera. Acesso em: 11 set. 2019.

ULRICH, R. S. et al. Stress recovery during exposure to natural and urban environments. Journal of Environmental Psychology, v. 11, n. 3, p. 201-230, 1991. Disponível em: https://www.sciencedirect.com/science/article/abs/pii/S0272494405801847?via\%3Dihub. Acesso em: 11 set. 2019.

ULRICH, R. S. View through a window may influence recovery from surgery. Science, v. 224, n. 4647, p. 420-421, 1984. Disponível em: http://science.sciencemag.org/content/224/4647/420.long. Acesso em: 11 set. 2019.

VALERA, S.; VIDAL, T. Privacidad y territorialidad. In: ARAGONÉS, J. I.; AMÉRIGO, M. (Orgs.). Psicología ambiental. Madrid: Pirámide, 2000. p. 123-147.

VAN DEN BERG, A. E. et al. Green space as a buffer between stressful life events and health. Social Science \& Medicine, v. 70, n. 8, p. 1203-1210, 2010. Disponível em:

https://www.sciencedirect.com/science/article/abs/pii/S0277953610000675?via\%3Dihub. Acesso em: 11 set. 2019.

VAN DEN BERG, A. E.; KOOLES, L.; VAN DER WULP, N. Y. Environmental preference and restoration: (how) are they related? Journal of Environmental Psychology, v. 23, n. 2, p. 135-146, 2003. Disponível em: https://www.sciencedirect.com/science/article/abs/pii/S0272494402001111. Acesso em: 11 set. 2019.

VOLP, C. M. LEA para populações diversas (Relatório Trienal apresentado a CPRT). Rio Claro: UNESP, 2000.

WALCH, J. M. et al. The effect of sunlight on postoperative analgesic medication use: a prospective study of patients undergoing spinal surgery. Psychosomatic Medicine, v. 67, n. 1, p. 156-163, 2005. Disponível em: https://insights.ovid.com/crossref?an=00006842-200501000-00022. Acesso em: 11 set. 2019. 
Felippe, M.; Hodecker, M.; Pichetti, D.; Kuhnen, A.

WILLIAMS, A. M.; IRURITA, V. F. Enhancing the therapeutic potential of hospital environments by increasing the personal control and emotional comfort of hospitalized patients. Applied Nursing Research, v. 18, n. 1, p. $22-28,2005$. Disponível em: https://www.sciencedirect.com/science/article/pii/S0897189704000874?via\%3Dihub. Acesso em: 11 set. 2019.

NOTA DO EDITOR (*): O conteúdo do artigo e as imagens nele publicadas são de responsabilidade do(s) autor(es). 